\title{
Recent progress in improving the safety and efficacy of chimeric antigen receptor T cell therapy
}

\author{
Yingying Yang, Yongxian Hu, Jiasheng Wang, He Huang \\ Zhejiang University School of Medicine First Affiliated Hospital
}

Abstract

Chimeric antigen receptor (CAR) T cell therapy has demonstrated unprecedented feat in a variety of malignancies, providing a transformative approach to treating patients with hematological malignancies and solid tumors. Although CAR-T cell therapy has shown remarkable anti-tumor activity, toxicities and tumor antigen escape have largely compromised its efficacy. In the case of solid-tumor management, it has shown modest results to date, likely due to heterogeneous antigen expression, an inhibitory tumor microenvironment, and other immunosuppressive factors. The predominant goal for this field now is to achieve more precise tumor recognition and design CARs with more robust proliferative ability. To this end, a multitude of novel CARs and new immunomodulatory antibodies are being developed and tested clinically. Intense efforts are underway to improve the engineering of synthetic immunotherapies and combine these strategies with other agents to amplify immune responses. In this review, we will discuss the current landscape of CAR-T cell therapy, with an emphasis on primary challenges that need to be addressed urgently. In addition, we characterize some newly designed CARs proposed for improving specificity and proliferation of CAR-T cells, offering new insights into improving safety and efficacy of CAR-T cell therapy.

Key words: chimeric antigen receptor, CAR T cell design, immunomodulator, checkpoint blockade

Submitted April 12, 2018; Accepted July 7, 2018; Published online August 29, 2018; Issued online November 25, 2018

Correspondence: He Huang, Md, PhD, Bone Marrow Transplantation Center, The First Affiliated Hospital, Zhejiang University School of Medicine79 Qingchun Road, Hangzhou, Zhejiang, 310003, China, E-mail: hehuangyu@ 126.com

\section{Introduction}

T cells modified to express chimeric antigen receptors (CARs) using transfer gene techniques have provided a compelling salvage treatment option for some lethal hematological diseases that have no alternative therapy. CARs are synthetic fusion proteins that are capable of specifically recognizing cell surface antigens. The most commonly used CARs typically consist of a variable portion of an antibody, known as an scFv (single-chain variable fragment) and a trans-membrane region that connects the extracellular domain to the cytoplasmic signaling domains ${ }^{1-3}$. The scFv-antigen interaction leads to activation of cytoplasmic signaling domains, resulting in $\mathrm{T}$ cell activation and proliferation. Subsequently, the expanded T cells may trigger cytolysis and secretion of cytokines to eliminate the target cells in a manner independent of major histocompatibility complex. Along with the emer- gence and development of CAR-T cell therapies, the designs of the CARs have undergone a long history of evolution, which has played a significant role in the development of CAR-T therapies. The first generation of CAR constructs consisted of the signaling molecule CD3z, which was essential to induce T-cell activation. However, the $\mathrm{T}$ cells activated by this initial design showed limited efficacy, leading to the development of the more potent second and third generations of CARs, which are further engineered to express multiple costimulatory domains ${ }^{3-8}$. A number of clinical trials have demonstrated significant antitumor activity of CAR-T cell therapy in the treatment of hematological malignancies. Despite efficacy in hematological diseases, however, the reported results of clinical experiments using this approach in solid tumors to date is not so encouraging ${ }^{9-12}$. Additionally, the safe clinical employment of CAR-T cell therapy has been largely limited by a number of signifi- 
cant safety concerns. In this mini-review, we review the current challenges encountered in the clinical application of CAR-T cell therapy, and highlight some feasible strategies aiming to overcome these emerging problems to achieve more effective CAR-T cell therapies.

\section{Modified CAR-T cell therapies for B Cell malig- nancies}

The past decade has witnessed a tremendous advancement of CAR-T cell therapy in the treatment of many advanced B cell malignancies. Clinical trials have demonstrated unprecedented clinical efficacy of CAR T cells against many aggressive $\mathrm{B}$ cell malignancies including acute lymphoblastic leukemia (B-ALL), chronic lymphocytic leukemia ${ }^{13-17}$ and B cell lymphomas ${ }^{18,19}$ by targeting $\mathrm{CD} 19^{1}, \mathrm{CD} 20^{20}, \mathrm{CD} 22^{21}$, or some other antigens. Among all of these antigens, the most compelling success has been achieved in CD19-targeted CAR-T cells for B-ALL, with complete remission (CR) rates as high as $90 \%$ 15,16,22-24. In August 2017, the first CD19-targeted CAR-T cell product was approved by the US Food and Drug Administration (FDA) for the treatment of pediatric and young adult patients with relapsed and/or refractory B-ALL.

The exciting clinical outcome achieved by CD19-targeted CAR-T cells across multiple institutions against leukemia and lymphoma has inspired the application of CAR-T cell therapies in the treatment of multiple myeloma (MM). Some of the potential targets for MM under investigation include $\mathrm{CD} 138^{25}, \mathrm{CD} 38^{26}$, $\mathrm{SLAM}^{27}$, $\kappa$ light chain $^{28}$, and B cell maturation antigen (BCMA) ${ }^{29}$. Among them, some early clinical trials have demonstrated significant anti-myeloma effects of CAR-T cells targeting BCMA. BCMA is an antigen expressed on mature B cells, including plasma cells and myeloma cells. In the first in-human clinical trial of BCMA-targeted CAR-T cell therapy, 12 patients with MM were enrolled and treated with an escalating dose of reengineered $\mathrm{T}$ cells ${ }^{29}$. More recently, Fan et al. reported promising clinical results of BCMA CAR-T cells in a phase-1 clinical trial, achieving up to a $100 \%$ objective response rate (ORR) in refractory/relapsed myeloma patients. Among these patients enrolled, 18 out of 19 patients achieved CR after receiving anti-BCMA CAR-T cell therapy over a long-term follow-up ${ }^{30}$. Nevertheless, CAR-T cell therapies for MM are in the preliminary stages of development. Researchers are continuing to look for unique plasma cell antigens expressed exclusively and uniformly on malignant plasma cells but not normal B cells.

\section{Challenges in solid tumors}

More recently, the success of CAR-T cell therapy in B cell malignancies sparked a search for applying it in solid tumors. Although certain progress has been made in early phase clinical studies, the wide application of CARs in the purview of solid tumors has been impeded by the lack of unique tumor associated antigens, an immunosuppressive tumor microenvironment, and limited trafficking of effector $\mathrm{T}$ cells to tumor sites ${ }^{31,32}$. Thus far, the overall outcomes of clinical trials are disappointing ${ }^{12,33}$. Nearly all clinical trials reported cross-reactivity caused by $\mathrm{T}$ cells attacking normal cells expressing low level of target antigen $^{32}$, a mechanism similar to B cell aplasia and hypo-immunoglobulin in the case of the CD19-specific CAR-T cells ${ }^{34}$. While the B-cell aplasia could be counteracted by infusion of immunoglobulin, damages to pivotal organs cannot be reversed and may lead to death in the worst cases ${ }^{35,36}$. Hence, a primary challenge is identifying tumor-specific antigens that can provide sufficient discrimination. The ideal tumor-restricted antigen is required to be expressed broadly and exclusively in tumor cells but is undetectable in normal cells. However, limited validated antigens and heterogeneous antigen expression pattern of solid tumors make the identification of such tumor-associated antigens very challenging. In this scenario, great effort should be made to further broaden the available target antigens by identifying target antigens expressed at low levels in healthy tissues, where depletion could be well tolerated in order to achieve more precise tumor recognition and ameliorate CAR-based toxicity.

Translating CAR-T cell therapy to solid tumors necessitates overcoming the inefficient trafficking of CAR-T cells to tumor sites. Chemokines are secreted by tumor cells and play an important role in trafficking and migration of effector T cells. Potential reasons for insufficient effector T-cell infiltration include the production by many human tumors of low levels of chemokines, and effector $\mathrm{T}$ cells lacking appropriate chemokine receptors of tumor-derived chemokine, all of which damage the homing capabilities of adoptively transferred T cells. Accordingly, it affords us the opportunity to correct the deficiencies in T-cell chemotaxis by transducing CAR-T cells with chemokine receptors. The consequent overexpression of chemokine receptors which match with the chemokines secreted by tumor cells could redirect migration of $\mathrm{T}$ cells towards tumors sites ${ }^{37}$. Several recent studies have proved the feasibility of genetically modifying CAR-T cells with the chemokine genes such as $\mathrm{CCR} 2 \mathrm{~b}^{38}$ and $\mathrm{CCR} 4^{39}$. In addition, the method of CAR-T cell delivery also exerts great impact on the effectiveness of $\mathrm{T}$ cells to penetrate the tumor tissue and migrate to the site of the tumor. Various preclinical and clinical studies 
have evaluated different ways of CAR-T cell delivery ${ }^{40,41}$. It has been proved that in contrast to conventional intravenous delivery, regional delivery of CAR-T cells promotes more efficient anti-tumor potency and $\mathrm{T}$ cell trafficking ${ }^{42}$.

\section{Provide a Bridge to allogenic-hematopoietic stem cell therapy (allo-HSCT) for patients with relapsed/refractory disease}

Adoptively transferred T-cell therapy is not only a stand-alone treatment, but also a bridge therapy to subsequent allo-HSCT. CD19-targeted immunotherapies have largely changed the paradigm of treatment for relapsed/ refractory B-ALL by providing an alternative salvage treatment option. Brentjens et al. first utilized CD19-targeted CAR-T cell therapy in patients with relapsed B-ALL who were thought to be ineligible for allo$\mathrm{HSCT}^{14}$. The patients enrolled in this study who achieved MRD-negative CR after CD19-targeted CAR-T cell therapy were permitted to undergo subsequent allo-HSCT. In another phase-1 dose-escalation clinical trial involving children and young adults with B-ALL, all of the ten enrolled patients achieved MRD-negative complete response, allowing for subsequent $\mathrm{HSCT}^{15}$. All of these promising clinical results highlight the dramatic antitumor ability of CD19-targeted CAR-T cells to induce MRD negative CR in patients with relapsed/refractory B-ALL who are unable to undergo HSCT. This could significantly improve poor prognoses by providing a bridge to allo-HSCT under optimal conditions.

\section{Concerns about CAR-T cell therapy}

\section{Toxicities of CAR-T cell therapy}

While CAR-T cell therapy has achieved compelling efficacy in treating hematological diseases, wide scale application of CAR-T cell therapy is impeded by severe toxicities, among which cytokine release syndrome (CRS) has been described as the most predominant and severe complication. CRS is a potentially life-threatening systemic inflammatory response, characterized by rapid elevation of a wide variety of cytokines released by activated $\mathrm{T}$ cells, such as interleukin-6 (IL-6), interferon-g $(\operatorname{IFN} \gamma)$, IL-15, IL-8, and/or IL-10 $14,34,43$. The major symptoms of CRS include high fever, hypotension, and hypoxia, with the most severe condition leading to widespread irreversible organ dysfunction and even death $^{22,44,45}$.

Moreover, damage of healthy tissues expressing low levels of tumor associated antigens (TAAs) by crossreactive $\mathrm{T}$ cells accounts for the so called in-target/offtumor effect. Ideally, the selected targeted antigen is supposed to be uniformly and specifically expressed on tumor cells while absent on healthy tissues. However, as demonstrated in many clinical trials, activation of $\mathrm{T}$ cells with engagement of normal tissue expressing low levels of TAAs has resulted in off-tumor effect, thus compromising the safety of CAR-T cell therapy. In the case of CD19-redirected CAR-T cell therapy, CD19 is not only expressed on malignant B cells, but also on normal B cells and other normal cells. Not unexpectedly, previous clinical data indicate CD19-redirected CAR-T cells attack both normal B cells and malignant B cells, resulting in profound B cell aplasia and hypo-immunoglobulin syndrome $^{34}$. Similar off-tumor effects have also been reported in solid tumors, because most TAAs are simultaneously expressed on normal tissues, albeit at low lev$\mathrm{els}^{9,35}$. Serious side effects can even led to death in the worst-case scenario. For example, fatal acute respiratory distress syndrome was reported in a phase- 1 trial with infusion of anti-ERBB2 CAR-T cells. The death was attributed to the damage of lung epithelium expressing low levels of HER2 by CAR-mediated cross-reactivity ${ }^{35}$. Similarly, on-target/off-tumor toxicity has been observed in other adoptive immunotherapies. For instance, a serious adverse event induced by affinity-enhanced TCRengineered T cells was reported in anti-MAGE-A3 TCR-T therapy ${ }^{46}$. In this case, effector $\mathrm{T}$ cells recognized the unexpected expression of MAGE-A3 in cardiac muscle and finally resulted in severe cardiovascular toxicity. The cross-reaction between activated $\mathrm{T}$ cells and normal tissues has dramatically raised safety concerns about the wider application of CAR-T cell therapy in solid tumors.

\section{Antigen negative escape}

Another main concern that has been raised is antigennegative relapse, rendering CAR-T cells ineffective against the relapsed tumor cells ${ }^{13,47}$. In clinical trials of CD19-redirected immunotherapy, a subset of patients treated with CD19-specific CAR-T cells experienced relapse with CD19-negative leukemia after an initial response despite persistence of CAR-T cells ${ }^{48,49}$. It has been confirmed that a substantial proportion of relapse cases can be attribute to antigen mutation or down-regulation, which have emerged as a primary challenge compromising the clinical efficacy of CD19-redirected CAR-T cell therapy ${ }^{50}$. Immune escape has also been documented in other hematological diseases ${ }^{51}$ and solid tumors $^{52}$. Nevertheless, antigen-negative immune escape could involve multiple complex mechanisms, including alternative antigen splicing, missense mutations, lineage switch induced by persisting CAR T immune pressure, or conversion to a myeloid phenotype $\mathrm{e}^{50,53,54}$. On this basis, it is suggested that future CARs should be designed to target more than one antigen to prevent an antigen-negative relapse, as will be discussed below. 


\section{Improving the safety and efficacy of CAR-T cell therapy}

Given the safety concerns about adoptively transferred $\mathrm{T}$ cell therapy, improving safety has emerged as a major focus area of current research. Here, we outline some new developments in preclinical and clinical studies to reduce the risks associated with CAR-T cell therapies.

\section{Bi-specific CARs}

The concerns mentioned above prompted researchers to improve the design of CARs to further mitigate toxicities and prevent antigen-loss relapses. The presence of multiple specific TAAs on the surface of tumor cells provides opportunities for simultaneous targeting of multiple antigens using dual-specific CAR-T cells. More recently, the concept of targeting more than one antigen simultaneously has been actively investigated in the scientific community. While single-specificity CAR-T cells will result in immune escape and outgrowth of antigen negative tumor cell subpopulations ${ }^{41}$, this does not seem to be the case for their counterparts of dual-specific $\mathrm{T}$ cells. In principle, there are several approaches that can be employed to target multiple antigens, and each one has its advantages and shortcomings. One strategy is to incorporate two binding domains into a single CAR structure, which is termed as bispecific $\mathrm{CAR}^{55}$. This bispecific CAR construct infuses two antigen-binding domains in tandem, showing a typical OR-gate signal recognition: it is activated by target cells that express either or both antigens. In comparison with their monospecific counterparts, bispecific CAR is superior in that they remain effective in the presence of a single antigen loss variant ${ }^{55}$. The effectiveness of tandem CD19/CD20 bi-specific CARs has been tested in several studies ${ }^{56}$, in which a significant reduction of both CD19 and CD20 expression on B cells was detected after just a short-term of co-incubation. Besides CD20 and CD19, other pan-B cell markers such as CD123 and CD22 can also be potential candidates for dual-targeted CARs ${ }^{57-59}$. For example, Ruella et al. evaluated the expression of CD123 in the samples from B-ALL patients. The CD19-CD123+ populations were found to be preexisting in most B-ALL samples at baseline, and persisted in patients who relapsed after CART19 therapy. They speculated that these CD19CD123 + cells were precursors of CD19-negative blasts, and were responsible for relapse after the administration of CD19-targeted T cells. Thus, investigators devised dual signaling CART123/CART19 T cells and tested them in a B-ALL xenografts model. As expected, dual CD19/ CD123 targeting CAR-T cells provided more potent effector activity against B-ALL in vivo in comparison with monospecific CAR-T cells ${ }^{57}$.

Surprisingly, compared with pooled administration of two different CAR-T cells, the bispecific construct was more efficacious with less toxicity ${ }^{55}$. Moreover, bispecific CAR-T cells exhibited synergistic effects when both antigens were simultaneously encountered, which could optimize the capacity for long term disease control ${ }^{60}$. In summary, targeting combination antigens by dual-signaling receptors has provided an effective preemptive approach to preventing relapses due to antigen escape.

\section{Optimization of the affinity of CAR design to reduce off-tumor toxicities}

Another approach for improving recognition specificity is to enhance CAR-T cell discrimination between tumor cells and normal cells based on antigen density. CAR-T cell therapy is an extremely sensitive treatment method, for which the threshold target antigen density required to induce activation of effector $\mathrm{T}$ cells and lysis of target tumor cells is considerably low ${ }^{61}$. Potential recognition of normal tissue expressing low density TAAs by effector T cells results in on-target/off-tumor effect, limiting a wide range of clinical application of CAR-T therapy. In order to improve its safety profiles, it is necessary to develop a strategy to reduce CAR sensitivity of normal tissues expressing relatively lower levels of target antigen, while retaining its antitumor activity. Indeed, the functional thresholds of antigen density became lower with the increasing level of the affinity of CARs for the ligand within a definite range ${ }^{62}$. Accordingly, affinity is of vital importance for adjusting the binding properties of $\mathrm{T}$ cells. CAR-T cells engineered with lower affinity CARs were confirmed to have comparable antitumor activity against tumor cells in comparison to their counterparts, but demonstrated impaired killing activity upon encountering healthy tissue expressing relatively lower level of TAAs $^{63}$. These results suggest that a defined affinity window exists that strike an optimal balance between efficient $\mathrm{T}$ cell response and emergence of on-target/offtumor autoimmunity ${ }^{64}$. It prompted us to ameliorate the safety profiles of CAR-based approaches by modulating CAR binding affinity for the target antigen, and generating CAR-T cells which are capable of preferentially recognizing the tumor cells expressing a high-density of target antigen. Thus far, the conception of tuning sensitivity of CAR-T cells to discriminate between tumor and normal cells has been practiced in several tumor models. The results have confirmed that it is feasible to improve CAR-T cell sensitivity according to antigen densities of tumor cells by tuning the CAR-TAA binding properties $^{63,65-68}$. In a pre-clinical study, investigators proposed a strategy to generate new CD38 antibodies with different affinities to CD38 ranging from 10- to 1000- fold lower relative to the normal ones ${ }^{66}$. They observed rapid tumor eradication with affinity-tuned anti-CD38 CAR-T cells and the absence of systemic toxicity on healthy hemato- 
poietic cells expressing CD38. Similar outcomes were observed in another study in which investigators tuned a CAR affinity based on the density of EGFR expression ${ }^{52}$. The results suggested that CARs with reduced affinity rendered $\mathrm{T}$ cells preferentially activated by high density EGFR on glioblastoma cells, but exhibited no apparent T-cell activation to lower densities of EGFR found on normal tissues ${ }^{65}$. All of these studies have shown that equipping CARs with an optimal affinity to the target antigen offers a solution to avert off-tumor side effects. However, the optimal affinity range appears to differ enormously when targeting different epitopes or antigens given the differences in each pathological situation ${ }^{63}$. To harness this feature, future studies are warranted to identify the optimal affinity window in a more context-dependent manner, and to search for antibodies that possess lower affinities but still maintain specificities.

\section{Incorporation of inducible safety switches}

In order to alleviate CRS and long-term B cell aplasia while maintaining potent antitumor activity, it is necessary to have control over CAR-T cell proliferation. Many safety switches have been designed to rapidly and selectively eliminate CAR-T cells in case of toxicities by incorporating a suicide gene. In principle, safety switches should meet several criteria: they should be expressed stably and efficiently in T cells without impairing the manufacturing process; the reagent turning on the gene should be well tolerated and be able to elicit T-cell dysfunction within a safe dose range. Safety switches that have been incorporated with CARs include $\mathrm{iC} 9^{69}$, herpes simplex thymidine kinase (HSV-TK), and epidermal growth factor receptor $(\mathrm{EGFR})^{70}$. Among all these safety switches, iC-9 is one of the most appealing safety strategies to eradicate CAR-T cells without causing side effects. It has been extensively tested in multicenter clinical trials ${ }^{71-73}$. Apoptosis mediated by iC 9 can be activated rapidly and irreversibly upon exposure to specific chemical inducer of dimerization (CID $)^{72,73}$. Compared with other suicide genes, iC9 proved to be a more efficient and specific way to induce apoptosis of effector $\mathrm{T}$ cells. Importantly, the sensitivity of iC9-transduced T cells to CID persists over time, providing a permanent control to terminate the effects of CAR-T cells. Moreover, the suicide gene terminates transduced $\mathrm{T}$ cells in a dose-dependent manner ${ }^{72}$. Given this advantage, when required, iC9 can reverse the expansion capacity of CAR-T cells, allowing for the reconstruction of $\mathrm{B}$ cells by adjusting the dose of the reagent without completely abrogating antitumor activity.

\section{Enhancement of proliferation and persistence of CAR-T cells}

\section{Armored CAR-T cells}

The inhibitory tumor microenvironment is one of the major challenges compromising the persistence and proliferation of transferred T cells, which is especially true in solid tumors. The solid tumor microenvironment is extremely immunosuppressive, which involves many inhibitory factors including regulatory $\mathrm{T}$ cells (Tregs) and inhibitory cytokines ${ }^{74}$. In an effort to control the negative effects of the tumor microenvironment on CAR-T cells, additional regulatory modulators would be incorporated. As supported by preclinical data, IL-12 is a proinflammatory cytokine shown to modulate the tumor microenvironment through multiple mechanisms ${ }^{75-78}$. Preclinical studies have already demonstrated that infusion of IL-12 can mediate potent in vivo antitumor activity in mice ${ }^{79}$. The multiple roles of IL-12 in adaptive and innate immunity provide the foundation and rationale to further modify CAR-T cells to secrete IL-12 using transgenic technology, in order to enhance persistence and resistance to immunosuppression. This construct is known as an 'armored' CAR-T cell ${ }^{80,81}$. Transgenic expression of IL-12 endowed CAR-T cells have improved proliferation ability compared with non-IL-12 secreting CAR-T cells in vitro and in vivo ${ }^{81}$. In a phase I clinical trial, Koneru et al. utilized these modified CAR-T cells with IL-12 secretion ability and administered them in patients with ovarian cancer. They were able to favorably modulate the tumor microenvironment and the endogenous immune system $^{82}$.

\section{Combination with checkpoint inhibitors}

Despite encouraging results in preclinical and clinical trials, the existence of different immunosuppressive pathways can restrict the full potential of adoptive T-cell therapy. Many tumors are capable of expressing ligands binding to inhibitory receptors (IRs) on T cells, such as programmed death 1 (PD1) and cytotoxic T lymphocyteassociated antigen 4 (CTLA-4), which lead to T cell dysfunction and exhaustion. The interaction between IRs and their ligands exerts profound immunosuppressive effects on T-cell function, which provides tumor cells an evasion mechanism from immunosurveillance ${ }^{83}$. As upregulation of inhibitory receptors is common among CAR-T cells, these pathways have been increasingly targeted in recent studies in an effort to neutralize their detrimental effects on T-cell function ${ }^{84}$. These agents are referred as immune checkpoint inhibitors such as PD-1 inhibitors which mediate unprecedented clinical benefits by targeting the PD-1/PD-L1 pathway ${ }^{85,86}$. Evidence from preclinical studies carried out in murine models indicated that anti-PD1 antibody could reverse T-cell 
exhaustion and enhance antitumor activity, with the potential to produce durable clinical responses ${ }^{87}$. More recent clinical trials using anti-PD-1 antibody reported remarkable clinical response in a significant fraction of patients with melanoma, renal cancer, ovarian cancer, and other malignancies ${ }^{88,89}$. In this regard, checkpoint inhibitors seem to be an ideal partner of adoptive $\mathrm{T}$ cell therapies, and indeed, a synergistic effect has been observed in some initial clinical trials ${ }^{90,91}$. It is worth noting, however, that various degrees of graft-versus-host disease were detected in a subset of cases, which was highly correlated with the reactivation of autoimmune reactive $\mathrm{T}$ cells ${ }^{86}$. Hence, toxicity profiles of combined therapy have to be carefully evaluated before wider clinical application can be considered.

Furthermore, based on the critical role that PD-1/ PD-L1 plays in T-cell exhaustion, it is appealing to divert the inhibitory signals into stimulatory ones. In pursuit of this objective, a study designed a costimulatory converter in the form of chimeric PD1/CD28 receptor. The T cells were transduced with both a CAR and a chimeric switchreceptor containing the extracellular domain of PD1 fused to the transmembrane domain ${ }^{92}$. In this way, when the PD1 portion of this switch-receptor engages its ligand, it will transmit an activating signal via the $\mathrm{CD} 28$ cytoplasmic domain, thus augmenting the clinical responses to CAR-T cell therapy ${ }^{93}$.

\section{Conclusion}

In this mini-review, we have discussed the current advances in the development of CAR-T cell therapy. Despite the great therapeutic efficacy exhibited by CAR-T cell therapy, its wide-scale application is still hampered by concerns of its intrinsic safety and longterm disease control.

Considering the commonness of in-target/off-tumor effect and antigen-negative relapse, a variety of genetic engineering approaches are being studied to further endow CAR-T cells with superior attributes, in order to enhance potency and safety. Some strategies were proposed to overcome toxicities and optimize tumor recognition specificity, including introduction of safety switches and tuning the affinity of CARs to recognize differential expression of antigens.

In addition, the combination of CAR-T cell therapy with other therapeutic entities has shown the potential to enhance the efficacy of CAR-T cell therapy, paving the way for combination immunotherapy in a clinical setting. For example, combining CAR-T cell therapy with additional regulatory modulators or checkpoint inhibitors can prevent rapid exhaustion of CAR-T cells within the immunosuppressive tumor microenvironment, enhancing the proliferation and persistence of CAR-T cells. Further developments in this field continue to evolve, which may require multi-disciplinary management and multi-center cooperation.

\section{Acknowledgments}

Not Applicable.

\section{Author's contribution}

Yingying Yang wrote the first draft of the paper; Jiasheng Wang and Yongxian Hu contributed revision of the manuscript; He Huang supervised the work and made final approval of the manuscript.

\section{Financial support}

This work was supported by grants from the National Natural Science Foundation of China (8177010467 and 8173000185).

\section{Conflict of interest}

The authors declare no conflicts of interest. Disclosure forms provided by the authors are available here.

\section{References}

1. Kochenderfer JN and Rosenberg SA. Treating B-cell cancer with T cells expressing anti-CD19 chimeric antigen receptors. Nat Rev Clin Oncol. 2013; 10: 267-76.

2. Maus MV, Grupp SA, Porter DL, and June CH. Antibodymodified T cells: CARs take the front seat for hematologic malignancies. Blood. 2014; 123: 2625-2635.

3. Sadelain M, Brentjens R, and Rivière I. The basic principles of chimeric antigen receptor design. Cancer Discov. 2013; 3: 388-98.

4. van der Stegen SJC, Hamieh M, and Sadelain M. The pharmacology of second-generation chimeric antigen receptors. Nat Rev Drug Discov. 2015; 14: 499-509.

5. Finney HM, Lawson AD, Bebbington CR, and Weir AN. Chimeric receptors providing both primary and costimulatory signaling in T cells from a single gene product. J. Immunol. 1998; 161: 2791-7.

6. Imai C, Mihara K, Andreansky M, Nicholson IC, Pui CH, Geiger TL, et al. Chimeric receptors with 4-1BB signaling capacity provoke potent cytotoxicity against acute lymphoblastic leukemia. Leukemia. 2004; 18: 676-84.

7. Jensen MC and Riddell SR. Designing chimeric antigen receptors to effectively and safely target tumors. Curr Opin Immunol. 2015; 33: 9-15.

8. Savoldo B, Ramos CA, Liu E, Mims MP, Keating MJC, arrum $\mathrm{G}$, et al. CD28 costimulation improves expansion and persis- 
tence of chimeric antigen receptor-modified T cells in lymphoma patients. J Clin Invest. 2011; 121: 1822-26.

9. Lamers CHJ, Sleijfer S, van Steenbergen S, van Elzakker P, van Krimpen B, Groot C, et al. Treatment of metastatic renal cell carcinoma with CAIX CAR-engineered T cells: clinical evaluation and management of on-target toxicity. Mol Ther. 2013; 21: 904-12.

10. Ahmed N, Brawley VS, Hegde M, Robertson C, Ghazi A, Gerken C, et al. Human Epidermal Growth Factor Receptor 2 (HER2)-Specific Chimeric Antigen Receptor-Modified T Cells for the Immunotherapy of HER2-Positive Sarcoma. J Clin Oncol. 2015; 33: 1688-96.

11. Louis CU, Savoldo B, Dotti G, Pule M, Yvon E, Myers GD, et al. Antitumor activity and long-term fate of chimeric antigen receptor-positive $\mathrm{T}$ cells in patients with neuroblastoma. Blood. 2011; 118: 6050-6.

12. Kakarla S and Gottschalk S. CAR T cells for solid tumors: armed and ready to go? Cancer J. 2014; 20: 151-155.

13. Maude SL, Frey N, Shaw PA, Aplenc R, Barrett DM, Bunin NJ, et al. Chimeric antigen receptor $\mathrm{T}$ cells for sustained remissions in leukemia. N Engl J. Med. 2014; 371: 1507-17.

14. Brentjens RJ, Davila ML, Riviere I, Park J, Wang X, Cowell LG, et al. CD19-targeted T cells rapidly induce molecular remissions in adults with chemotherapy-refractory acute lymphoblastic leukemia. Sci Transl Med. 2013; 5: 177ra38.

15. Lee DW, Kochenderfer JN, Stetler-Stevenson M, Cui YK, Delbrook C, Feldman SA, et al. T cells expressing CD19 chimeric antigen receptors for acute lymphoblastic leukaemia in children and young adults: a phase 1 dose-escalation trial. Lancet. 2015; 385: 517-28.

16. Porter DL, Levine BL, Kalos M, Bagg A, and June CH. Chimeric antigen receptor-modified $\mathrm{T}$ cells in chronic lymphoid leukemia. N Engl J Med. 2011; 365: 725-33.

17. Porter DL, Hwang WT, Frey NV, Lacey SF, Shaw PA, Loren $\mathrm{AW}$, et al. Chimeric antigen receptor $\mathrm{T}$ cells persist and induce sustained remissions in relapsed refractory chronic lymphocytic leukemia. Sci Transl Med. 2015; 7: 303ra139.

18. Turtle CJ, Hanafi LA, Berger C, Gooley TA, Cherian S, Hudecek M, et al. CD19 CAR-T cells of defined CD4 + : CD8 + composition in adult B cell ALL patients. J. Clin. Invest. 2016; 126: $2123-38$.

19. Brudno JN and Kochenderfer JN. Chimeric antigen receptor T-cell therapies for lymphoma. Nat Rev Clin Oncol. 2018; 15: 31-46.

20. Till BG, Jensen MC, Wang J, Qian X, Gopal AK, Maloney DG, et al. CD20-specific adoptive immunotherapy for lymphoma using a chimeric antigen receptor with both CD28 and 4-1BB domains: pilot clinical trial results. Blood. 2012; 119: 3940-50.

21. Haso W, Lee DW, Shah NN, Stetler-Stevenson M, Yuan CM, Pastan IH, et al. Anti-CD22-chimeric antigen receptors targeting B-cell precursor acute lymphoblastic leukemia. Blood. 2013; 121: 1165-74.

22. Davila ML, Riviere I, Wang X, Bartido S, Park J, Curran K, et al. Efficacy and toxicity management of $19-28 z$ CAR T cell therapy in B cell acute lymphoblastic leukemia. Sci Trans1 Med. 2014; 6: 224ra25.

23. Maude SL, Teachey DT, Porter DL, and Grupp SA. CD19-targeted chimeric antigen receptor T-cell therapy for acute lymphoblastic leukemia. Blood. 2015; 125: 4017-23.

24. Turtle CJ, Hanafi LA, Berger C, Hudecek M, Pender B, Robinson E, et al. Immunotherapy of non-Hodgkin's lymphoma with a defined ratio of CD8 + and CD4 + CD19-specific chimeric antigen receptor-modified T cells. Sci Transl Med. 2016; 8: 355 ra116.

25. Guo B, Chen Meixia, Han Qingwang, Hui Fan, Dai Hanren, Zhang Wenying, et al. CD138-directed adoptive immunotherapy of chimeric antigen receptor (CAR)-modified $\mathrm{T}$ cells for multiple myeloma. J Cell Immunother. 2016; 2: 28-35.

26. Drent E, Groen RW, Noort WA, Themeli M, Lammerts van Bueren JJ, Parren PW, et al. Pre-clinical evaluation of CD38 chimeric antigen receptor engineered $\mathrm{T}$ cells for the treatment of multiple myeloma. Haematologica. 2016; 101: 616-25.

27. Gogishvili T, Danhof S, Prommersberger S, Rydzek J, Schreder $\mathrm{M}$, Brede C, et al. SLAMF7-CAR T cells eliminate myeloma and confer selective fratricide of SLAMF7 normal lymphocytes. Blood. 2017; 130: 2838-47.

28. Ramos CA, Savoldo B, Torrano V, Ballard B, Zhang H, Dakhova $\mathrm{O}$, et al. Clinical responses with $\mathrm{T}$ lymphocytes targeting malignancy-associated $\kappa$ light chains. J. Clin. Invest. 2016; 126: $2588-96$.

29. Ali SA, Shi V, Maric I, Wang M, Stroncek DF, Rose JJ, et al. T cells expressing an anti-B-cell maturation antigen chimeric antigen receptor cause remissions of multiple myeloma. Blood. 2016; 128: 1688-1701.

30. Fan Frank, Zhao Wanhong, Liu JieHe, Aili, Chen Yinxia, Cao Xingmei, et al. Durable remissions with BCMA-specific chimeric antigen receptor (CAR) -modified T cells in patients with refractory/relapsed multiple myeloma. J Clin Oncol. 2017; 35 (18_suppl): LBA3001-LBA3001.

31. Kershaw MH, Westwood JA, Parker LL, Wang G, Eshhar Z, Mavroukakis SA, et al. A phase I study on adoptive immunotherapy using gene-modified $\mathrm{T}$ cells for ovarian cancer. Clin Cancer Res. 2006; 12: 6106-15.

32. Park JR, Digiusto DL, Slovak M, Wright C, Naranjo A, Wagner $\mathrm{J}$, et al. Adoptive transfer of chimeric antigen receptor redirected cytolytic $\mathrm{T}$ lymphocyte clones in patients with neuroblastoma. Mol Ther. 2007; 15: 825-33.

33. Lamers CH, Sleijfer S, Vulto AG, Kruit WH, Kliffen M, Debets $\mathrm{R}$, et al. Treatment of metastatic renal cell carcinoma with autologous T-lymphocytes genetically retargeted against carbonic anhydrase IX: first clinical experience. J Clin Oncol. 2006; 24: e20-e22.

34. Brentjens RJ, Rivière I, Park JH, Davila ML, Wang X, Stefanski J, et al. Safety and persistence of adoptively transferred autologous CD19-targeted T cells in patients with relapsed or chemotherapy refractory B-cell leukemias. Blood. 2011; 118: 481728.

35. Morgan RA, Yang JC, Kitano M, Dudley ME, Laurencot CM 
and Rosenberg SA. Case report of a serious adverse event following the administration of $\mathrm{T}$ cells transduced with a chimeric antigen receptor recognizing ERBB2. Mol. Ther. 2010; 18: 843-51.

36. Parkhurst MR, Yang JC, Langan RC, Dudley ME, Nathan DA, Feldman SA, et al. T cells targeting carcinoembryonic antigen can mediate regression of metastatic colorectal cancer but induce severe transient colitis. Mol Ther. 2011; 19: 620-6.

37. Kershaw MH, Wang G, Westwood JA, Pachynski RK, Tiffany HL, Marincola FM, et al. Redirecting migration of T cells to chemokine secreted from tumors by genetic modification with CXCR2. Hum. Gene Ther. 2002; 13: 1971-80.

38. Craddock JA, Lu A, Bear A, Pule M, Brenner MK, Rooney CM, et al. Enhanced tumor trafficking of GD2 chimeric antigen receptor $\mathrm{T}$ cells by expression of the chemokine receptor CCR2b. J Immunother. 2010; 33: 780-8.

39. Di Stasi A, De Angelis B, Rooney CM, Zhang L, Mahendravada A, Foster AE, et al. T lymphocytes coexpressing CCR4 and a chimeric antigen receptor targeting CD30 have improved homing and antitumor activity in a Hodgkin tumor model. Blood. 2009; 113: 6392-6402.

40. Katz SC, Burga RA, McCormack E, Wang LJ, Mooring W, Point GR, et al. Phase I Hepatic Immunotherapy for Metastases Study of Intra-Arterial Chimeric Antigen Receptor-Modified T-cell Therapy for CEA + Liver Metastases. Clin Cancer Res. 2015; 70: 773-9.

41. Brown CE, Alizadeh D, Starr R, Weng L, Wagner JR, Naranjo A, et al. Regression of Glioblastoma after Chimeric Antigen Receptor T-Cell Therapy. N Engl J. Med. 2016; 375: 2561-9.

42. Adusumilli PS, Cherkassky L, Villena-Vargas J, Colovos C, Servais E, Plotkin J, et al. Regional delivery of mesothelin-targeted CAR T cell therapy generates potent and long-lasting CD4-dependent tumor immunity. Sci Transl Med. 2014; 6: $261 \mathrm{ra} 151$.

43. Lee DW, Gardner R, Porter DL, Louis CU, Ahmed N, Jensen $\mathrm{M}$, et al. Current concepts in the diagnosis and management of cytokine release syndrome. Blood. 2014; 124: 188-95.

44. Brudno JN and Kochenderfer JN. Toxicities of chimeric antigen receptor T cells: recognition and management. Blood. 2016; 127: 3321-30.

45. Neelapu SS, Tummala S, Kebriaei P, Wierda W, Gutierrez C, Locke FL, et al. Chimeric antigen receptor T-cell therapyassessment and management of toxicities. Nat Rev Clin Oncol. 2018; 15: 47-62.

46. Linette GP, Stadtmauer EA, Maus MV, Rapoport AP, Levine BL, Emery L, et al. Cardiovascular toxicity and titin crossreactivity of affinity-enhanced $\mathrm{T}$ cells in myeloma and melanoma. Blood. 2013; 122: 863-71.

47. De Munter S, Ingels J, Goetgeluk G, Bonte S, Pille M, Weening K, et al. Nanobody Based Dual Specific CARs. Int J Mol Sci. 2018; 19: 1-11.

48. Topp MS, Gökbuget N, Zugmaier G, Degenhard E, Goebeler ME, Klinger M, et al. Long-term follow-up of hematologic relapse-free survival in a phase 2 study of blinatumomab in patients with MRD in B-lineage ALL. Blood. 2012; 120: 5185-7.

49. Topp MS, Gökbuget N, Zugmaier G, Klappers P, Stelljes M, Neumann S, et al. Phase II Trial of the Anti-CD19 Bispecific T Cell-Engager Blinatumomab Shows Hematologic and Molecular Remissions in Patients With Relapsed or Refractory B-Precursor Acute Lymphoblastic Leukemia. J Clin Oncol. 2014 2014; 32: 4134-40.

50. Gardner R, Wu D, Cherian S, Fang M, Hanafi LA, Finney O, et al. Acquisition of a CD19-negative myeloid phenotype allows immune escape of MLL-rearranged B-ALL from CD19 CART-cell therapy. Blood. 2016; 127: 2406-10.

51. Evans AG, Rothberg PG, Burack WR, Huntington SF, Porter DL, Friedberg JW, et al. Evolution to plasmablastic lymphoma evades CD19-directed chimeric antigen receptor $\mathrm{T}$ cells. $\mathrm{Br} \mathrm{J}$ Haematol. 2015; 171: 205-9.

52. Genßler S, Burger MC, Zhang C, Oelsner S, Mildenberger I, Wagner M, et al. Dual targeting of glioblastoma with chimeric antigen receptor-engineered natural killer cells overcomes heterogeneity of target antigen expression and enhances antitumor activity and survival. Oncoimmunology. 2016; 5: e1119354.

53. Sotillo E, Barrett DM, Black KL, Bagashev A, Oldridge D, Wu $\mathrm{G}$, et al. Convergence of Acquired Mutations and Alternative Splicing of CD19 Enables Resistance to CART-19 Immunotherapy. Cancer Discov. 2015; 5: 1282-95.

54. Jacoby E, Nguyen SM, Fountaine TJ, Welp K, Gryder B, Qin H, et al. CD19 CAR immune pressure induces B-precursor acute lymphoblastic leukaemia lineage switch exposing inherent leukaemic plasticity. Nat Commun. 2016; 7: 1-10.

55. Schneider D, Xiong Y, Wu D, Nölle V, Schmitz S, Haso W, et al. A tandem CD19/CD20 CAR lentiviral vector drives on-target and off-target antigen modulation in leukemia cell lines. J Immunother Cancer. 2017; 5: 1-17.

56. Martyniszyn A, Krahl AC, André MC, Hombach AA, and Abken H. CD20-CD19 Bispecific CAR T Cells for the Treatment of B-Cell Malignancies. Hum. Gene Ther. 2017; 28: 1147-57.

57. Ruella M, Barrett DM, Kenderian SS, Shestova O, Hofmann TJ, Perazzelli J, et al. Dual CD19 and CD123 targeting prevents antigen-loss relapses after CD19-directed immunotherapies. J Clin Invest. 2016; 126: 3814-26.

58. Lee L, Draper B, Chaplin N, Philip B, Chin M, Galas-Filipowicz D, et al. An APRIL-based chimeric antigen receptor for dual targeting of BCMA and TACI in multiple myeloma. Blood. 2018; 131: 746-58.

59. Schubert ML, Hoffmann JM, Dreger P, Müller-Tidow C, and Schmitt M. Chimeric antigen receptor transduced T cells: Tuning up for the next generation. Int. J. Cancer. 2018; 142: 173847.

60. Grada Z, Hegde M, Byrd T, Shaffer DR, Ghazi A, Brawley VS, et al. TanCAR: A Novel Bispecific Chimeric Antigen Receptor for Cancer Immunotherapy. Mol Ther Nucleic Acids. 2013; 2: e105.

61. Watanabe K, Terakura S, Martens AC, van Meerten T, Uchi- 
yama S, Imai M, et al. Target antigen density governs the efficacy of anti-CD20-CD28-CD3 $\zeta$ chimeric antigen receptormodified effector CD8 + T cells. J Immunol. 2015; 194: 91120.

62. Han C, Sim SJ, Kim SH, Singh R, Hwang S, Kim YI, et al. Desensitized chimeric antigen receptor $\mathrm{T}$ cells selectively recognize target cells with enhanced antigen expression. Nat Commun. 2018; 9: 468.

63. Arcangeli S, Rotiroti MC, Bardelli M, Simonelli L, Magnani CF, Biondi A, et al. Balance of Anti-CD123 Chimeric Antigen Receptor Binding Affinity and Density for the Targeting of Acute Myeloid Leukemia. Mol Ther. 2017; 25: 1933-45.

64. Zhong S, Malecek K, Johnson LA, Yu Z, Vega-Saenz de Miera E, Darvishian F, et al. T-cell receptor affinity and avidity defines antitumor response and autoimmunity in T-cell immunotherapy. Proc Natl Acad. Sci. 2013; 110: 6973-78.

65. Caruso HG, Hurton LV, Najjar A, Rushworth D, Ang S, Olivares S, et al. Tuning Sensitivity of CAR to EGFR Density Limits Recognition of Normal Tissue While Maintaining Potent Antitumor Activity. Cancer Res. 2015; 75: 3505-18.

66. Drent E, Themeli M, Poels R, de Jong-Korlaar R, Yuan H, de Bruijn J, et al. A Rational Strategy for Reducing On-Target Off-Tumor Effects of CD38-Chimeric Antigen Receptors by Affinity Optimization. Mol Ther. 2017; 25: 1946-58.

67. Liu X, Jiang S, Fang C, Yang S, Olalere D, Pequignot EC, et al. Affinity-Tuned ErbB2 or EGFR Chimeric Antigen Receptor T Cells Exhibit an Increased Therapeutic Index against Tumors in Mice. Cancer Res. 2015; 75: 3596-607.

68. Park S, Shevlin E, Vedvyas Y, Zaman M, Park S, Hsu YS, et al. Micromolar affinity CAR T cells to ICAM-1 achieves rapid tumor elimination while avoiding systemic toxicity. Sci Rep. 2017; 7: 1-15.

69. Hoyos V, Savoldo B, Quintarelli C, Mahendravada A, Zhang M, Vera J, et al. Engineering CD19-specific T lymphocytes with interleukin-15 and a suicide gene to enhance their anti-lymphoma/leukemia effects and safety. Leukemia. 2010; 24: 1160-70.

70. Wang X, Chang WC, Wong CW, Colcher D, Sherman M, Ostberg JR, et al. A transgene-encoded cell surface polypeptide for selection, in vivo tracking, and ablation of engineered cells. Blood. 2011; 118: 1255-63.

71. Zhou X, Di Stasi A, Tey SK, Krance RA, Martinez C, Leung $\mathrm{KS}$, et al. Long-term outcome after haploidentical stem cell transplant and infusion of $\mathrm{T}$ cells expressing the inducible caspase 9 safety transgene. Blood. 2014; 123: 3895-905.

72. Diaconu I, Ballard B, Zhang M, Chen Y, West J, Dotti G, et al. Inducible Caspase-9 Selectively Modulates the Toxicities of CD19-Specific Chimeric Antigen Receptor-Modified T Cells. Mol Ther. 2017; 25: 580-92.

73. Yagyu S, Hoyos V, Del Bufalo F, and Brenner MK. An Inducible Caspase-9 Suicide Gene to Improve the Safety of Therapy Using Human Induced Pluripotent Stem Cells. Mol Ther. 2015; 23: $1475-85$.

74. Mirzaei HR, Rodriguez A, Shepphird J, Brown CE, and Badie
B. Chimeric Antigen Receptors T Cell Therapy in Solid Tumor: Challenges and Clinical Applications. Front Immunol. 2017; 8: 1850 .

75. Kilinc MO, Aulakh KS, Nair RE, Jones SA, Alard P, Kosiewicz $\mathrm{MM}$, et al. Reversing tumor immune suppression with intratumoral IL-12: activation of tumor-associated T effector/memory cells, induction of $\mathrm{T}$ suppressor apoptosis, and infiltration of CD8 + T effectors. J Immunol. 2006; 177: 6962-73.

76. Watkins SK, Egilmez NK, Suttles J, and Stout RD. IL-12 rapidly alters the functional profile of tumor-associated and tumor-infiltrating macrophages in vitro and in vivo. J Immunol. 2007; 178: 1357-62.

77. Broderick L, Brooks SP, Takita H, Baer AN, Bernstein JM, and Bankert RB. IL-12 reverses anergy to T cell receptor triggering in human lung tumor-associated memory T cells. Clin Immunol. 2006; 118: 159-69.

78. Vignali DA and Kuchroo VK. IL-12 family cytokines: immunological playmakers. Nat Immunol. 2012; 13: 722-28.

79. Brunda MJ, Luistro L, Warrier RR, Wright RB, Hubbard BR, Murphy M, et al. Antitumor and antimetastatic activity of interleukin 12 against murine tumors. J Exp Med. 1993; 178: 1223-30.

80. Zhang L, Morgan RA, Beane JD, Zheng Z, Dudley ME, Kassim $\mathrm{SH}$, et al. Tumor-infiltrating lymphocytes genetically engineered with an inducible gene encoding interleukin-12 for the immunotherapy of metastatic melanoma. Clin Cancer Res. 2015; 21: 2278-88.

81. Koneru M, Purdon TJ, Spriggs D, Koneru S, and Brentjens RJ. IL-12 secreting tumor-targeted chimeric antigen receptor T cells eradicate ovarian tumors. Oncoimmunology. 2015; 4: $1-11$.

82. Koneru M, O'Cearbhaill R, Pendharkar S, Spriggs DR, and Brentjens RJ. A phase I clinical trial of adoptive T cell therapy using IL-12 secreting MUC-16 (ecto) directed chimeric antigen receptors for recurrent ovarian cancer. J Transl Med. 2015; 13: 102.

83. Rowshanravan B, Halliday N, and Sansom DM. CTLA-4: a moving target in immunotherapy. Blood. 2018; 131: 58-67.

84. Barber DL, Wherry EJ, Masopust D, Zhu B, Allison JP, Sharpe $\mathrm{AH}$, et al. Restoring function in exhausted CD8 T cells during chronic viral infection. Nature. 2006; 439: 682-7.

85. Wang RF and Wang HY. Immune targets and neoantigens for cancer immunotherapy and precision medicine. Cell Res. 2017; 27: 11-37.

86. Postow MA, Sidlow R, and Hellmann MD. Immune-Related Adverse Events Associated with Immune Checkpoint Blockade. N Engl J Med. 2018; 378: 158-68.

87. Odorizzi PM, Pauken KE, Paley MA, Sharpe A, and Wherry EJ. Genetic absence of PD-1 promotes accumulation of terminally differentiated exhausted CD8 + T cells. J Exp Med. 2015; 212: 1125-37.

88. Daskivich TJ and Belldegrun A. Re: Safety, Activity, and Immune Correlates of Anti-PD-1 Antibody in Cancer. Eur Urol. 2015; 67: 816-7. 
89. Brahmer JR, Tykodi SS, Chow LQ, Hwu WJ, Topalian SL, Hwu $\mathrm{P}$, et al. Safety and activity of anti-PD-L1 antibody in patients with advanced cancer. N Engl J Med. 2012; 366: 2455-65.

90. Sun C, Dotti G, and Savoldo B. Utilizing cell-based therapeutics to overcome immune evasion in hematologic malignancies. Blood. 2016; 127: 3350-9.

91. John LB, Devaud C, Duong CP, Yong CS, Beavis PA, Haynes $\mathrm{NM}$, et al. Anti-PD-1 antibody therapy potently enhances the eradication of established tumors by gene-modified $\mathrm{T}$ cells. Clin Cancer Res. 2013; 19: 5636-46.

92. Ankri C, Shamalov K, Horovitz-Fried M, Mauer S, and Cohen
CJ. Human T cells engineered to express a programmed death $1 / 28$ costimulatory retargeting molecule display enhanced antitumor activity. J Immunol. 2013; 191: 4121-9.

93. Liu X, Ranganathan R, Jiang S, Fang C, Sun J, Kim S, et al. A Chimeric Switch-Receptor Targeting PD1 Augments the Efficacy of Second-Generation CAR T Cells in Advanced Solid Tumors. Cancer Res. 2016; 76: 1578-90.

https://doi.org/10.31547/bct-2018-003

Copyright (c) 2018 APBMT. All Rights Reserved. 